\title{
Analysis of underflowing of residential areas and protection from urban groundwater
}

\author{
Alexandra Bakulina ${ }^{1,}{ }^{*}$, Viktor Bilenko ${ }^{1}$, Evgeny Rudomin ${ }^{1}$, Sergey Borychev ${ }^{2}$, Anastasiya \\ Silkina ${ }^{1}$, and Vadim Fetisov ${ }^{1}$ \\ ${ }^{1}$ Ryazan Institute (branch) of Moscow Polytechnic University, Pravo-Lybedskaya Str., 26/53, 390000, \\ Ryazan, Russia \\ ${ }^{2}$ Ryazan State Agrotechnological University Named after P.A. Kostychev, Kostycheva Str., 1, \\ 390044, Ryazan, Russia
}

\begin{abstract}
The article discusses the main provisions for the protection of urban buildings from groundwater and the main causes of flooding of residential areas. Also known and proposed by us ways of solving the problem are analyzed. In recent years, intensive construction has been going on in areas that were previously considered unsuitable for construction: wetlands, floodplains of rivers and streams, ravines, etc. without deep study of changes in the hydrological regime of the adjacent territory. Activities are offered in flooded areas: elimination of the causes of flooding - channel lining; sealing of water pipes and collectors, installation of storm sewers; sealing of buried structures: basement walls, foundations; drainage lowering groundwater to a safe depth. With our participation, a drainage system has been developed, with drainage water diversion to the floodplain of the Oka River.
\end{abstract}

\section{Introduction}

Among the priority tasks of urban construction, the need to protect housing from harmful environmental influences due to a sharp exacerbation of the ecological and hydrogeological situation [1,2], in particular due to the rise in the groundwater level, has been put forward [3$5,7]$. At the present time, an intensive development of underground space is underway in urban construction. Residential buildings with underground garages in one and sometimes in two tiers are being built, basements of houses are being developed for commercial purposes, road junctions are being built at different levels, the construction of underground pedestrian crossings is continuing, a network of sewer collector tunnels and other structures buried under the surface of the earth is developing. All these structures must be protected from the penetration of groundwater. Designers must solve the problem of flooding using the entire arsenal of tools - from the correct placement of residential buildings in the city to the choice of types of houses and utilities.

\footnotetext{
* Corresponding author: nio@rimsou.ru
} 


\section{Materials and Methods}

Flooding is a complex hydrogeological and engineering-geological process, in which, as a result of changes in the water regime and the balance of the territory, the levels (heads) of groundwater and soil moisture increase, exceeding the critical values adopted for this type of development and violating the necessary conditions for the construction and operation of facilities [5, 8-10].

In Russia, there are thousands of cities where flooding of the buried parts of buildings and basements is noted. Flooding is an unfavorable process, since it increases the costs of construction (in watered soils it is more expensive) and the operation of developed territories (due to watering of the basement and basement floors of buildings). It increases the corrosive activity of the environment when watering the upper layers of soils, especially heaving, increases the aggressiveness of groundwater, which is typical for built-up areas, especially when there are losses from heating networks, sewerage and water supply networks.

In most cases, waterlogging and flooding of the territory is the result of some combination of reasons, which in the general case can be natural (natural) and artificial (anthropogenic, technogenic - associated with human activities). A variety of reasons for waterlogging, taking into account the individuality of the area and the architectural and planning solution at each construction site, makes the development of a water reduction system a unique task for each construction site.

Based on the identification of the causes of waterlogging and the location of flooded areas, it is possible to develop an effective and economical design of drainages and protect the buried parts of the building from flooding.

The causes of flooding can be divided into natural and anthropogenic [11 - 15].

Natural reasons include geological, topographic, hydrological causes of waterlogging.

Geological reasons for waterlogging are the features of the geological structure from the surface to a depth of 6-10 m (as applied to landscape construction). The number of soil layers and the water-physical characteristics of each layer can vary over a wide range.

Topographic reasons for waterlogging are the features of the relief of the construction area. The presence of hills and elevated ridges separated by hollows and thalweg, natural terraces, closed depressions and river valleys - all these relief elements make the territory especially attractive as an object of landscape construction, but at the same time, the complexity of the engineering development of the territory increases significantly. The tasks of dewatering and water disposal are especially relevant in the lowered parts of the relief, where the runoff of surface and ground waters is concentrated.

Hydrological reasons for waterlogging are the influence of the natural hydrographic network (rivers, streams, lakes, etc.) on the water regime of the adjacent territory. First of all, it is the backwatering of the groundwater of the territory by the waters of the receiving water.

Artificial causes of flooding of territories. In this group of reasons, the following can be distinguished: the transformation of the relief, the creation of structures on the path of the natural movement of surface and ground waters, the effect of the water level in artificial reservoirs, fluid leakage from pipelines and canals.

Relief transformation. As a result of work on the organization of the relief and vertical planning, providing for a significant lowering of the design elevations in relation to the original relief, the groundwater level (GWL) may turn out to be at a depth less than the depth corresponding to the drainage rate.

Creation of barriers to the natural movement of groundwater. After the construction of a structure with a deep underground part (below the natural groundwater level), the flow of groundwater becomes "supported by an underground dam". As a result, the GWL rises at the upper boundary of the structure, creating preconditions for the appearance of a flooded zone. 
In addition to the formation of a flooded zone at the upper boundary of the structure, prerequisites are created for the occurrence of contact filtration along the underground contour of the structure and the development of the suffusion process.

Fluid leaks from pipelines. Leakage of water from water supply and sewerage facilities and gutters can cause an increase in GWL, especially in urban conditions.

\section{Results}

Many organizations are working on this problem. The employees of the Ryazan Institute (branch) of the Moscow Polytechnic University also do not stand aside from this problem. The problems considered are also typical for the city of Ryazan, located on the right bank of the Oka River at the confluence of the Trubezh River, in the center of the East European Plain, on a territory cut by many ravines and small rivers.

For which the sources of flooding are:

- water losses in water supply and sewer pipes. Industrial effluents and tap water entering the ground form technogenic underground water horizons. From year to year, the level of these waters rises and begins to flood the basements;

- large built-up areas. Condensate formed under structures and asphalt pavement does not evaporate, accumulates in the ground and forms a perforation;

- unsatisfactory operation of storm sewers, and in particular clogging of water intakes with household waste and leaves.

- construction of underground structures. Tunnels, crossings, industrial and civil buildings with a basement, underground garages built across the stream play the role of a water-retaining dam, contributing to a rise in the level of groundwater, etc.

In recent years, intensive construction has been going on in areas that were previously considered unsuitable for construction: wetlands, floodplains of rivers and streams, ravines, etc. without deep study of changes in the hydrological regime of the adjacent territory. For example, the problem of flooding basements arose in the Kalnoe microdistrict of the city of Ryazan. In Figure 1, the arrow indicates the area to be heated. And on the longitudinal profile, we see a site where the surface water drainage system and groundwater drainage system should be well organized. One of the reasons that caused this problem is the development of the territory of the swamp for construction (Figure 2). Thus, the natural drainage of the microdistrict territory was disturbed. 


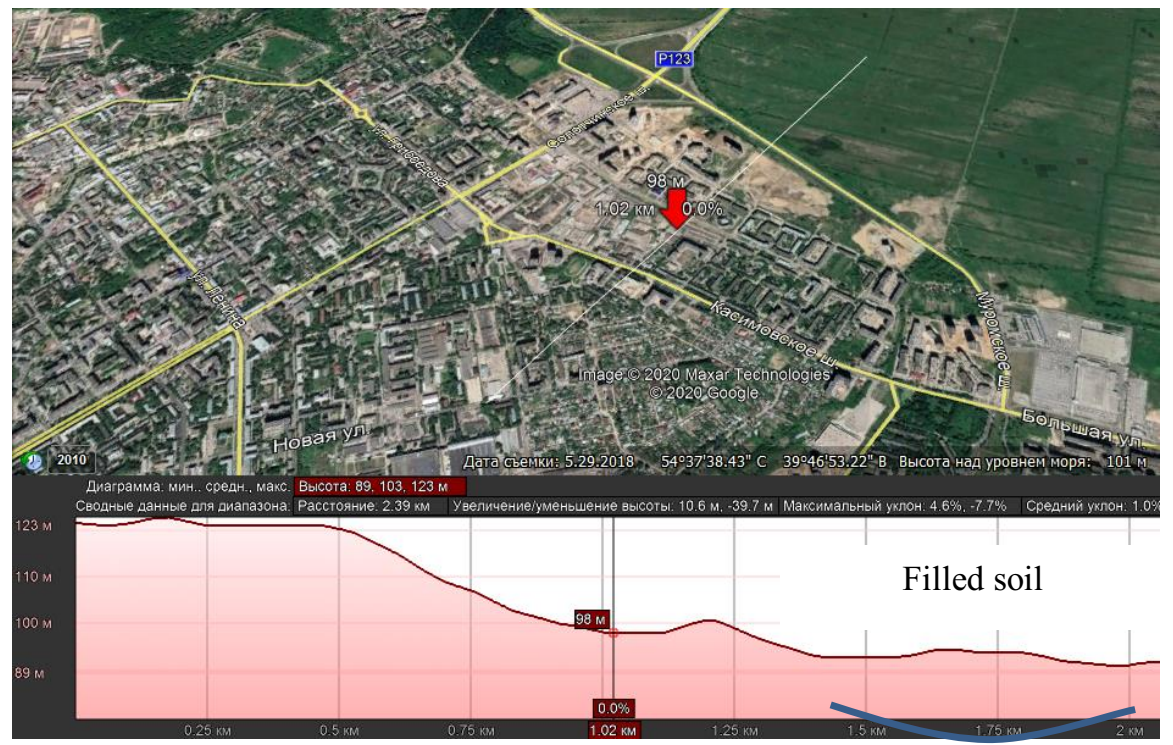

Fig. 1. Flooding zone in the Kalnoe microdistrict and a swamp area converted into a construction site.
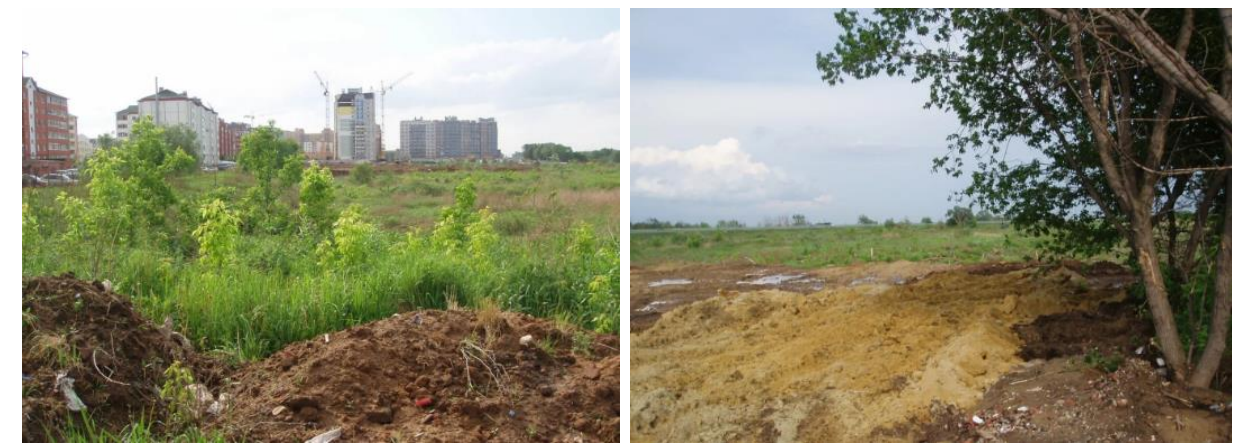

Fig. 2. One of the reasons that caused this problem is the development of the territory of the swamp for construction.

In addition, as a result of the survey, it was revealed that the drainage system works unsatisfactorily (Figure 3), and the blind area around many houses is destroyed (figure 4).
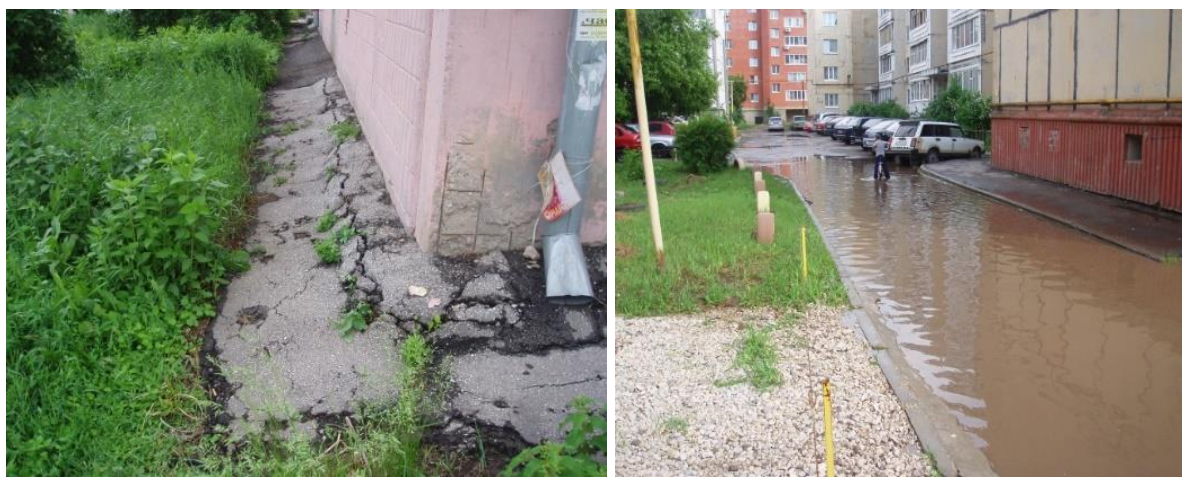

Fig. 4. Drainage system works unsatisfactorily, and the blind area around many houses is destroyed. 
We have proposed activities in flooded areas:

1. Elimination of the causes of flooding - channel lining; sealing of water pipes and collectors, installation of storm sewers;

2. Sealing of buried structures: basement walls, foundations;

3. Drainage - lowering groundwater to a safe depth.

With our participation, a drainage system has been developed, shown in Figure 6, with drainage water diversion to the floodplain of the Oka River.

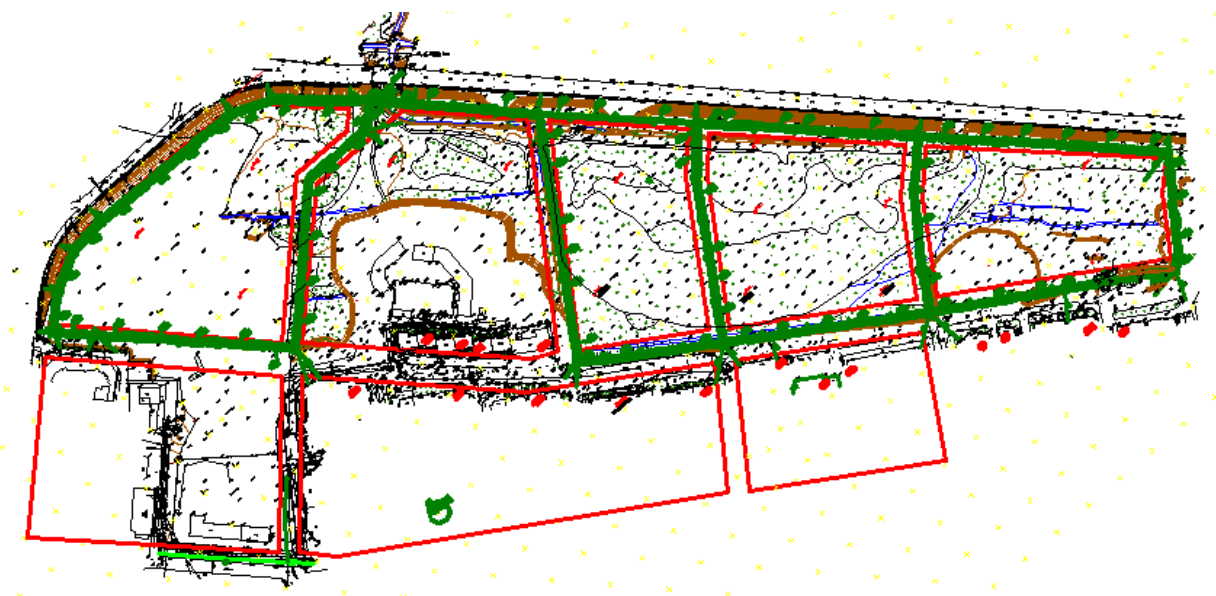

Fig. 5. Drainage system in the Kalnoe microdistrict.

The drainage system is shown in Figure 6. To protect the projected site from groundwater and flooding, during the flood of the Oka River, main networks have been designed to divert drainage water.

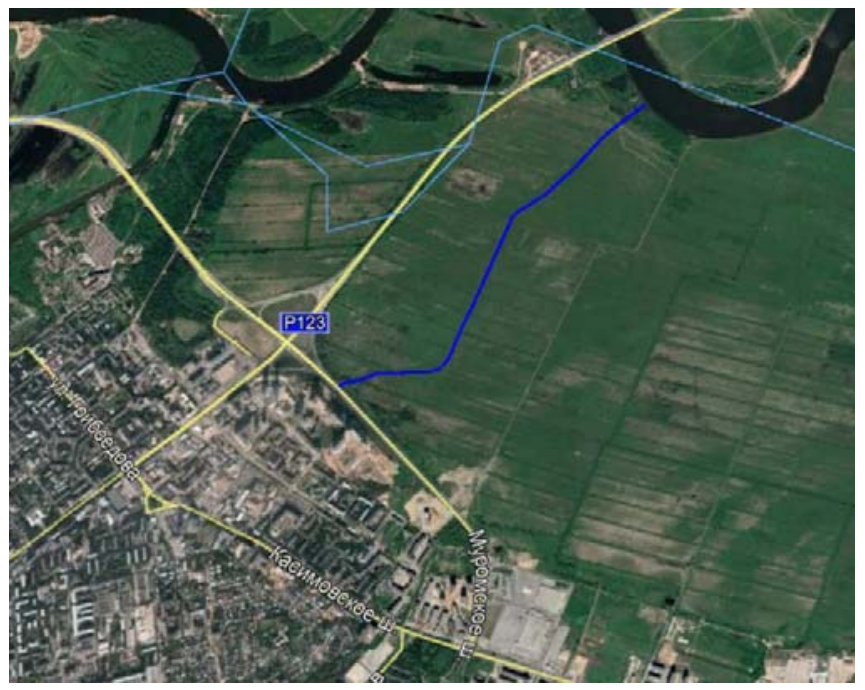

Fig. 6. Drainage system in the Kalnoe microdistrict.

The starting point of the profile is calculated from the elevations of the basement and the bottom of the foundation slab of the projected buildings located on this site, taking into account the laying of wall drainage of the projected buildings. Polyethylene pipes are used to receive drainage water. The project provides for the connection of the projected network 
to the existing channel with a head device.

As a result of a rise in the water level in the Oka River above the critical mark, flooding of the projected drainages may occur. To prevent this from happening, a "floating wing" valve is installed in front of the head in the well at the outlet, which operates in automatic mode [6].

Employees of the Department of Industrial and Civil Engineering of the Ryazan Institute (branch) of the Moscow Polytechnic University conduct research work to protect urban development from groundwater. We have developed a method for protecting the foundation of a building from flooding on heaving soils at the level of the invention [7], the diagram of which is shown in Figure 7.

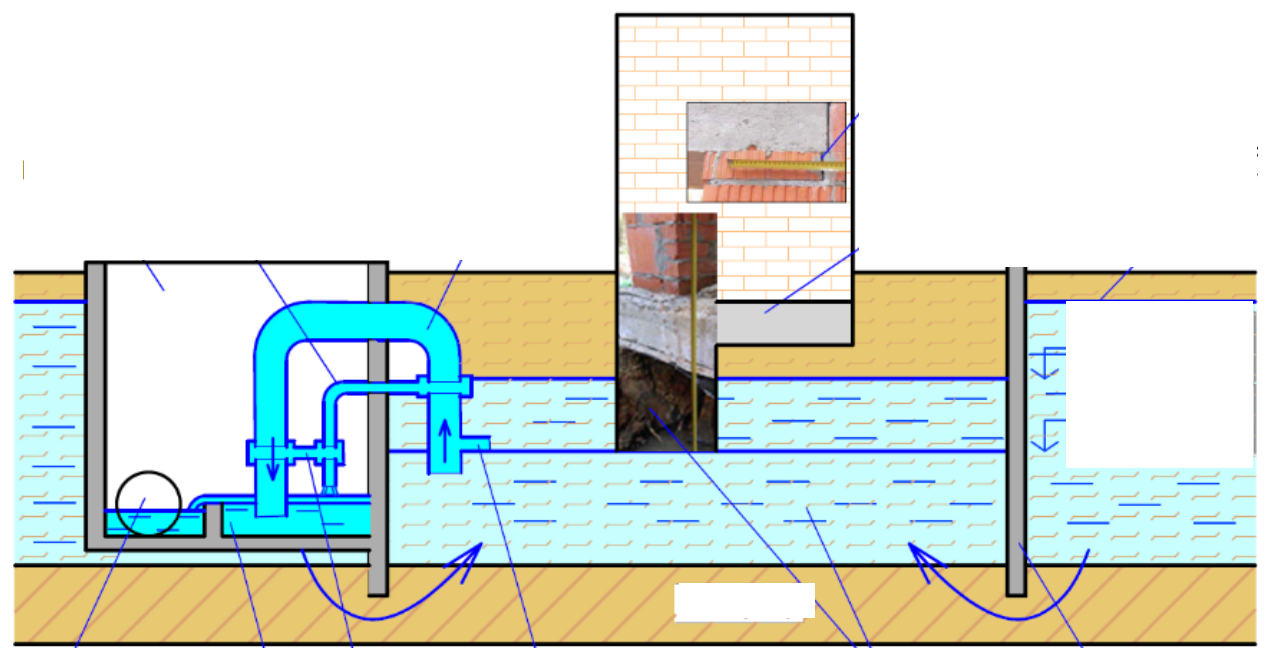

Fig. 7. Demonstration diagram of a method for protecting the foundation of a building from flooding on heaving soils.

The method includes creating a pit, immersing the foundation body into it and backfilling with non-porous soil. In front of the building, it is planned to place an additional support blocking block, for example, a wall in the ground, with a mark of the structure below the depth of seasonal freezing. A drainage system is provided somewhat remote from the building, creating conditions for maintaining a constant water level by taking excess groundwater, using a permanently operating device in the form of a siphon, which has a starting mechanism made in the form of interconnected water level sensor tubes, an ejector, a well, a closed collector with a discharge pipe. The water level sensor tube is communicated on the one hand with the suction part of the siphon through an opening made in the side wall (partition) of the well, and on the other hand, by means of an ejector, with the drain part of the siphon located in an additional section of the siphon chamber at the bottom of the well. The lower end of the sensor tube is placed in the additional chamber above the level of the overflow wall of the siphon chamber, and the end of the drain part of the siphon and the outlet pipe of the closed collector is below it.

The technical result consists in increasing the efficiency of protection of foundations from deformations of frost-hazardous foundations in the conditions of their deep seasonal freezing and lowering of the groundwater level, as well as the process of accelerating the drainage of groundwater during thawing of soils in the zones of operation of buildings on heaving soils.

In addition, the department has developed a method for creating multi-layer waterproofing of wall drainage with horizontal elastic needles. The technical result of the development consists in increasing the reliability and durability of buildings and structures, as well as increasing the drainage capacity of the filtering material with the least labor 
intensity, using the available sheets of geotextile material. Below is a technical description of the proposed method and Figure 9 shows a diagram of a wall with wall drainage that implements this method.
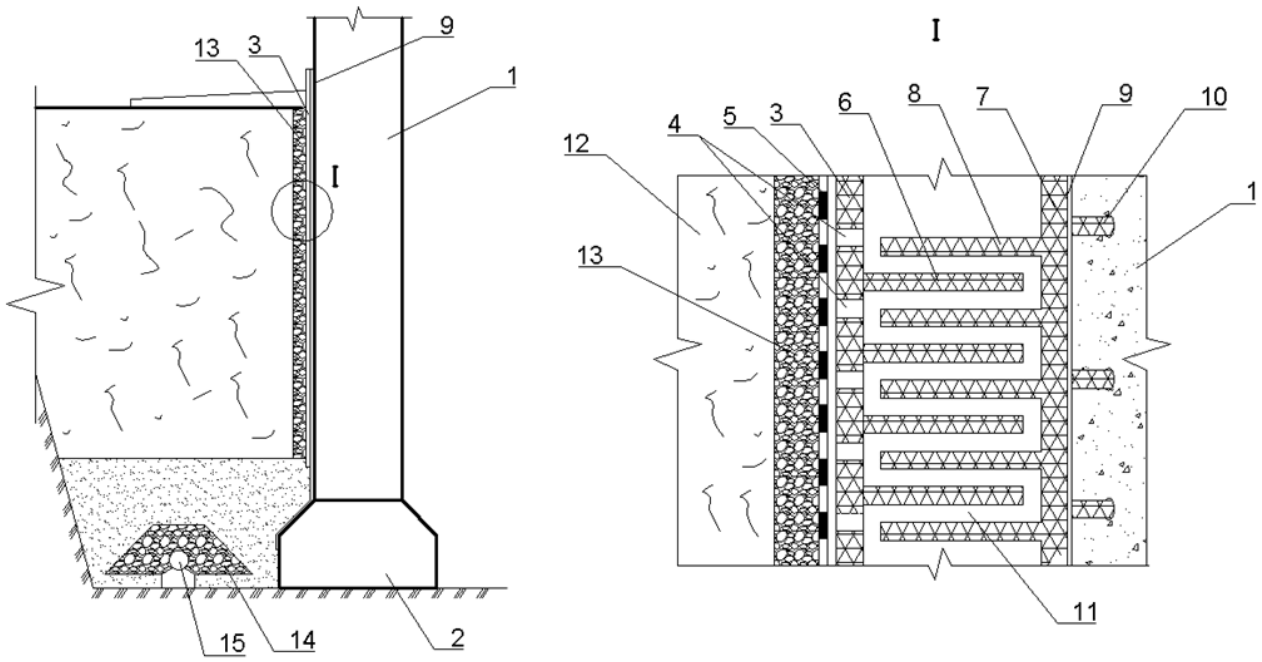

Fig. 8. Shows a diagram of a wall with wall drainage that implements this method.

A method of creating a multilayer waterproofing of a wall drainage with horizontal elastic needles includes a free-standing underground structure of an underground part of a concrete wall 1 of a building or structure, which contains a foundation 2 , an outer layer of a perforated thermally bonded waterproof material of geotextile 3 with through holes 4 with a mesh 5 , made by horizontally connecting elastic needles 6 . The concrete wall 1 of the foundation 2 is protected by a waterproof layer 7 of geotextile material with horizontally binding elastic needles 8 , which is glued to additional waterproofing in the form of bitumen mastic 9, and anchor ribs 10. In the space between the elastic needles 6 and 8 in the transverse direction, elastic needles made with a displacement relative to each other at different levels through the calculated distances, and combined into a closed system with horizontal and vertical passageways 11 from the base of the foundation 2 of the wall to the top of the permeable blind area of the soil. In the space between the layers of the soil surface 12 and the thermally bonded material, the geotextile 3 is covered with material 13, which does not include sand (for example, gravel or pebbles). This contributes to a significant additional protection of the material of the geotextile 3 with through holes 4 with a mesh 5. The removal of the incoming water is carried out in the filling 14 of the drain pipe 15 connected to a discharge manifold (not shown). The inner waterproof layer 7 from the side of the building foundation slab serves as a waterproof protective material of geotextile, made, for example, additionally on a bitumen-based mastic 8 with a thickness of at least $2 \mathrm{~mm}$ of the wall surface 1 of the foundation 2 of a building or structure during construction and at the stage of operation of the outer layer of thermally bonded geotextile 3 with a thickness of at least $3 \mathrm{~mm}$. Internal channels 11 serve to drain the filtering layer of water passing through the filtering material 13 , then through the mesh 5 and through holes 4 in the geotextile, then into the permanent channels 11 and into the backing 14 of the drainage pipe 15. The purpose of the mesh 5 is to protect the through holes 4 in the geotextile 3 from clogging with particles through a waterpermeable material 13 .

Taking into account the above, the peculiarity of calculating the location of horizontal connecting elastic needles on the inner part of the waterproofing layer of thermally bonded geotextile is determined by the known formulas of groundwater inflow, i.e. the head of 
groundwater, the depth of water inside the collector, the radius of influence of drainage, the diameter of the outlet pipe are taken into account.

Sealing layers of geotextiles with their horizontal elastic needles are oriented coaxially and with displacement relative to each other at different levels through design distances, thereby forming closed compartments inside the device as a whole. At the same time, from the side of the building foundation, the waterproofing, as in the analogue, is additionally fastened with anchor ribs oriented inwardly to the concrete body of the foundation wall (slab) and anchored after its installation and an additional protective layer in the form of insulation made of bituminous mastic. In general, this serves as a good protective basis for localizing the zones of waterproofing of the foundation walls (slabs) of buildings and structures.

The outer layer of geotextile with through holes, covered with mesh and filter material, which consists of particles of the same size, serve as a filter and at the same time a barrier against soil suffusion. The use of perforated thermally bonded geotextile - a material with elastic needles, allows the inner layer to be used to form vertical channels in the direction of drainage, then it is diverted into a permanent drainage pit. The pores of the thermally bonded geotextile from the outside are silted up faster, therefore, through holes are used in such a sheet 4 . In this technical solution, perforated thermally bonded geotextiles are used as a private solution to form a durable waterproof layer and as a means of providing through holes in it and fastening from the inside of the binders horizontal elastic needles.

\section{Conclusion}

1. Considered the reasons for the aggravation of the ecological and hydrogeological situation, in particular, due to the rise in the level of groundwater and measures to protect housing from the harmful effects of the environment.

2. The proposed devices allow to increase the protection of foundations from flooding.

3. The devices developed at the Department of SGS will improve the protection of foundations from flooding and ensure the operational reliability of buildings, at a low cost of implementing the proposed methods.

\section{References}

1. V. Chechevichkin, N. Vatin, Appl. Mech. Mater. 641-642 409-415 (2014) https://doi.org/10.4028/www.scientific.net/AMM.641-642.409.

2. V.N. Chechevichkin, N.I. Vatin, Mag. Civ. Eng. $50 \quad 67-74 \quad$ (2014) https://doi.org/10.5862/MCE.50.7.

3. V.A. Bilenko et al., Materials of scientific-practical conference. "Increasing the efficiency of construction production based on new materials and innovative technologies" (Ryazan, 2013)

4. Building regulations 2.06.15-85 "Engineering protection of territories from flooding and flooding"

5. https://zstrela.ru/projects/magazine/sections/obustroystvo-uchastka/ prichiny _ podtopleniya - territoriy

6. Ya.V. Bochkarev, V.A. Bilenko, 1186727 USSR, MKI E 02 V 7/26 No. 3719062 / 2915; declared 02/03/84; publ. 10/23/85, Bul. No. 39

7. E.N. Rudomin, S.E. Rudomin, V.A. Bilenko, M.I. Golubenko, A method of protecting the foundation of a structure in the area of a building to maintain a moist regime on heaving soils, Patent for invention No. 2707315 (2019) 
8. W.B. Blower, W.B. Wilkinson, Groundwater Eff. Geotechn.Eng: Proc. 9th Eur. Conf. Soil Mech. and Found. Eng. (Rotterdam, Brookfield, 1989)

9. N. Borreman, Tijdschr. Watervoorz. En afvalwaterbehandel 26, 776-779 (1988)

10. G.E. Blight, Groundwater Eff. Geotechn. Eng: Proc. 9th Eur. Conf. Soil Mech. and Found. Eng. (Rotterdam, Boston, 1987)

11. J.J.Cushing, Underground discharge for downspouts and sump pumps МКИ Е $02 B$ 11/00, E 04 D 13/08, НКИ 405/43

12. R.N. Craig, B. Simpson, Tunnel Conctr. 90: Pap. Conf. Inst. Mining and Met. (London, 1990)

13. M. Eiswirth, The 31st International Geological Congress (Rio de Janeiro, 2000)

14. H.A. El-Sayed, Cemento 2, 84-102 (1990)

15. G.D. Geldof, E.N. Boere, F.H.M. Ven et al., PT/Civ. Tehn. 1, $43-48$ (1987) 